\title{
NOVEL THIN FILM POLYMER FOAMING TECHNIQUE FOR LOW AND ULTRA LOW-K DIELECTRICS
}

\author{
B. Krause, G.H. Koops, N.F.A. van der Vegt and M. Wessling \\ University of Twente, \\ Membrane Technology Group \\ P.O. Box 217, 7500 AE Enschede, The Netherlands \\ Tel.: +31-53-489-2957, Fax: +31-53-489-4611 \\ B.Krause@ct.utwente.nl
}

\author{
M. Wübbenhorst, J. van Turnhout \\ Delft University of Technology, \\ Polymer Materials and Engineering \\ Julianalaan 136, 2628 BL Delft, The Netherlands \\ Tel.: +31-15-278-6940, \\ M.R.Wubbenhorst@tnw.tudelft.nl
}

\section{INTRODUCTION}

As minimum device dimensions continue to shrink and on-chip device densities grow, signal distortion caused by capacitive coupling and crosstalk between the interconnections will increase. The current insulator material for on-chip applications is silicon dioxide $(\mathrm{k}=$ 3.9 - 4.2). The next generations of microchips require interlayer dielectrics with dielectric constants below 2.2 $[1,2]$. Although several high temperature resistant polymers have been synthesized recently [3], it seems that the ultra low-k range $(\mathrm{k}<2.2)$ remains out of reach. Therefore new concepts based on porous structures have been introduced. These concepts are broadly based on two different principles: (i) thermal decomposition of a block copolymer composed of a thermally stable block and a thermally unstable one [4-7], (ii) thermal treatment of layers consisting of high $T_{g}$ polymers and thermally unstable components $[8,9]$. These techniques allow the fabrication of low and ultra low-k dielectrics. However, both techniques have several drawbacks: (i) the cost intensive preparation of specially designed block copolymers, (ii) the time-consuming heat treatment of the applied coatings for removal of the chemically labile and "volatile" component(s).

In this paper we present an alternative thin film polymer foaming technique based on the following principle: (1) a polymer film is saturated with $\mathrm{CO}_{2}$ at high pressure, (2) the polymer/gas mixture is quenched into a supersaturated state by reducing the pressure and increasing the temperature, and consequently (3) nucleation and growth of gas cells dispersed throughout the polymer sample evolve rendering films with a microcellular structure. We will illustrate that our experimental method can be used to adjust the foam morphology with respect to porosity and cell size, which allows one to reduce the dielectric constant systematically.

\section{EXPERIMENTAL}

Materials Matrimid $^{\circledast} 5218$ (Figure 1) was obtained from Ciba Specialty Chemicals Ltd., Basel, Switzerland. N-Methylpyrrolidone (NMP) and Hexane were obtained from Fluka, Germany. All chemicals were used without further purification. Carbon dioxide was purchased from Praxair having a purity larger than $99.99 \%$.

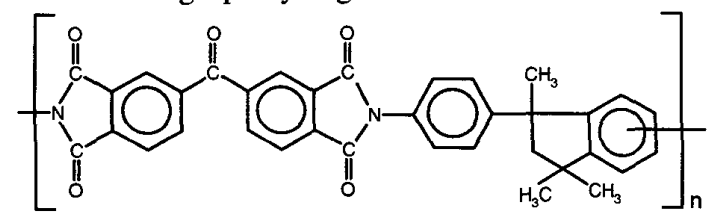

Figure 1. Chemical structure of Matrimid ${ }^{\circledR}$.

Foam Formation Matrimid ${ }^{\circledR}$ was used for film formation $(\sim 100 \mu \mathrm{m}$ thick) by solution casting ( $20 \mathrm{wt}$.$\%$ polyimide in N-Methylpyrrolidone) on a glass plate. The cast films were dried in a nitrogen atmosphere at 75 ${ }^{\circ} \mathrm{C}$ for 4 hours. Subsequently, the homogeneous dense films were removed from the glass and further dried under vacuum at $150{ }^{\circ} \mathrm{C}$ for several weeks to remove the last traces of solvents. The prepared polymer films were cut into $4 \mathrm{~cm} \times 4 \mathrm{~cm}$ pieces and placed in a pressure vessel connected to a carbon dioxide cylinder. The samples were then saturated with carbon dioxide at a saturation temperature $\left(\mathrm{T}_{\mathrm{sat}}\right)$ and saturation pressure $\left(P_{\text {sat }}\right)$ for 2 hours. Subsequently, the carbon dioxide was quickly released from the pressure vessel (within a 1 $\mathrm{sec})$. After removing the gas-saturated polymer film from the pressure vessel, the sample was immersed during a fixed time (foaming time) in a glycerol bath maintained at the desired foaming temperature $\left(T_{\text {foam }}\right)$. 


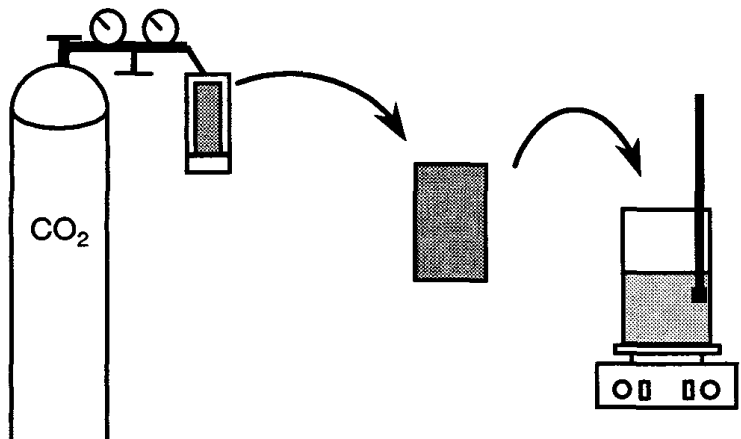

Figure 2. Schematic drawing of the solid state foaming process. The solid polymer film is saturated with carbon dioxide at temperatures below the glass transition temperature of the polymer/gas mixture. Subsequently, the saturated film is transferred to a heated glycerol bath.

A schematic drawing of the experimental procedure is shown in Figure 2. The foamed samples were next quenched in an ethanol / water (50/50) mixture, washed in ethanol and dried under vacuum at $30^{\circ} \mathrm{C}$ for 24 hours to remove traces of ethanol and water. During the transfer procedure of the gas saturated polymer from the pressure vessel to the heating part diffusion of carbon dioxide out of the polymer matrix takes place. This effect leads to a reduced carbon dioxide concentration near the surface and results in a dense skin layer, which covers the porous foam core.

Characterization Methods The density of the dense films and foams were analyzed by applying the floatation weight loss method (ASTM D-792) with hexane as liquid. Hexane uptake in the foamed sample could not be observed during the measurement, which process would overestimate the true density. The densities obtained are average values of the entire polymer sample, i.e., the foamed core part including the integral dense skin. These densities were used to obtain the void fraction of the porous polymers.

The microcellular morphologies of the foamed samples were investigated using a Joel JSM-5600 LV scanning electron microscope (SEM). The samples were freeze fractured in liquid nitrogen and sputter coated (Balzers/Union 040) with gold at an argon pressure of $13 \mathrm{~Pa}$ for $2 \mathrm{~min}$ at a current of $14 \mathrm{~mA}$.

Dielectric properties of the well dried film samples were measured by a broadband dielectric spectrometer using a combination of three dielectric analysers for (partially) overlapping frequency ranges: a frequency response analyser (Schlumberger 1260) with a custom-made dielectric interface $\left(10^{-2}-10^{4} \mathrm{~Hz}\right)$, a Hewlett-Packard 4284A precision LCR-meter $\left(10^{2}-10^{6} \mathrm{~Hz}\right)$ and a HP4194A RF-spectrometer $\left(10^{6}-1.8 \times 10^{9} \mathrm{~Hz}\right)$. For the dielectric experiments, squared pieces were cut from dense or foamed films, which then were sputtered on both sides with circular Au electrodes of $30 \mathrm{~mm}$ in diameter to provide good electrical contact to the parallel plate electrodes and to ensure a well defined electrically active sample area. Careful determination of the sample thickness and area together with calibrations of the electrode and analyzer configuration resulted in absolute $\mathrm{k}$ values within an uncertainty of typically $3 \%$.

\section{RESULTS}

The microcellular morphologies are fixed by three thermodynamic variables: $P_{\text {sat }}, T_{\text {sat }}$ and $T_{\text {foam. }}$. The discontinuous experimental approach employed allowed to independently vary the carbon dioxide content of the homogeneous polymer/gas mixture and the temperature at which the actual expansion was performed. The thermodynamic variables of the foaming process have been investigated in detail and are well understood in terms of the cellular structures obtained [10]. Microcellular morphologies are primary determined by the extent of super-saturation during foaming $\left(\mathrm{CO}_{2}\right.$ concentration in the film and the foaming temperature). At a fixed carbon dioxide concentration foamed structures can only be obtained at foaming temperatures located between the glass transition temperature $\left(T_{g}\right)$ of the polymer gas mixture and an upper critical foaming temperature $\left(T_{\text {upper }}\right)$, which is usually close to the glass transition temperature of the parent polyimide [10]. The $T_{g}$ depression, controlling the temperature window in which foam formation is enabled, strongly depends on the dissolved amount of carbon dioxide. The foaming temperature window for Matrimid ${ }^{(\infty}$ and the corresponding porosities of the foam samples are shown in Figure 3.

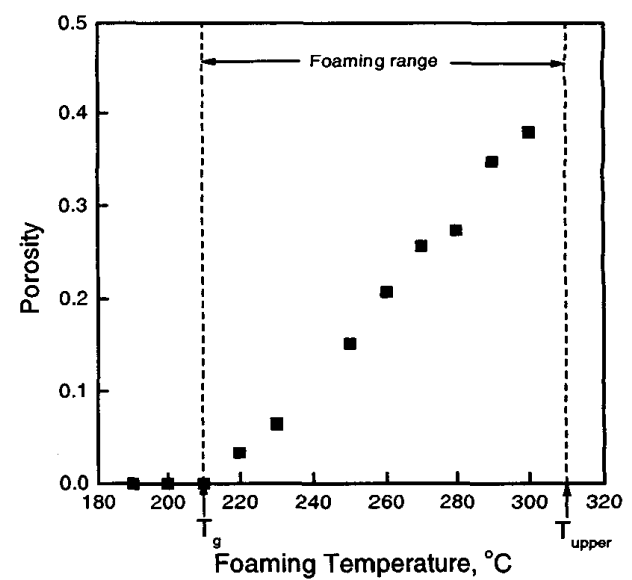

Figure 3. Porosity of Matrimid ${ }^{\circledast}$ at different foaming temperatures. The samples were saturated with 50 bar carbon dioxide for 2 hours at room temperature. Foaming times of 30 seconds were used.

In the foaming temperature range the mass porosity can be fine-tuned by varying the foaming temperature. The density of Matrimid ${ }^{\circledR}$ samples decreases to approxi- 
mately $63 \%$ of that of the parent polymer at the maximum foaming temperature of $300^{\circ} \mathrm{C}$. The prepared foam morphologies of Matrimid ${ }^{\circledR}$ display a nanometercellular morphology with characteristic cell dimensions between 20 to $50 \mathrm{~nm}$, shown in Figure 4. Such small cells have not been reported earlier using the solid state foaming technique. The main reason for these extraordinary small cells is the high carbon dioxide solubility in Matrimid ${ }^{\circledR}$ and in polyimides in general which leads to an increased number of nuclei formed.

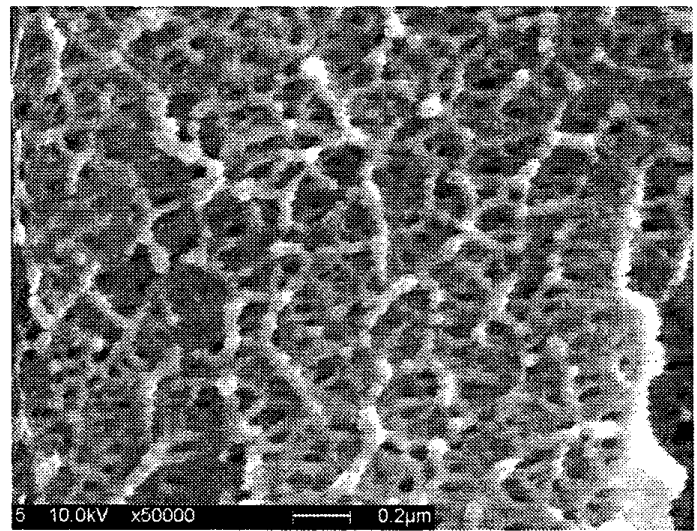

Figure 4. SEM micrograph of Matrimid foamed at 250 ${ }^{\circ} \mathrm{C}$. Prior to foaming the sample was saturated with 50 bar carbon dioxide for 2 hours at room temperature. Foaming times of 30 seconds were used. Magnification 50000, the white horizontal bar indicates $200 \mathrm{~nm}$

As expected, these porous materials show a correspondingly reduced dielectric constant ranging from $k=3.0$ (dense Matrimid ${ }^{\circledR}$ ) to about 2.0 for Matrimid $^{\circledR}$ foamed at $290{ }^{\circ} \mathrm{C}$. For an extensive characterization of the dielectric properties we have measured all samples in a wide frequency $\left(10^{-1}-10^{9}\right.$ $\mathrm{Hz})$ and temperature range $\left(25^{\circ}-240^{\circ} \mathrm{C}\right)$.

According to Figures 5 and 6, Matrimid ${ }^{\circledR}$ shows a clear relation between decreasing permittivity and increasing porosity, i.e. increasing content of air having the ultimate permittivity of one. Assuming a two-phase dielectric material, we have modeled the permittivity by two realistic rules of mixtures, which account for spherical inclusions $(\mathrm{k}=1)$ in a polymer matrix (Maxwell-Garnett theory and Looyenga- LandauLifshitz theory). Furthermore, the upper bound for $\mathrm{k}\left(\mathrm{v}_{\mathrm{air}}\right)$ obtained by the simple linear rule of mixture, and the lower bound, which corresponds to a layer model, are given as a reference. The permittivity $k\left(v_{\text {air }}\right)$ for Matrimid $^{\circledR}$ follows roughly the predicted curve for spherical inclusions.

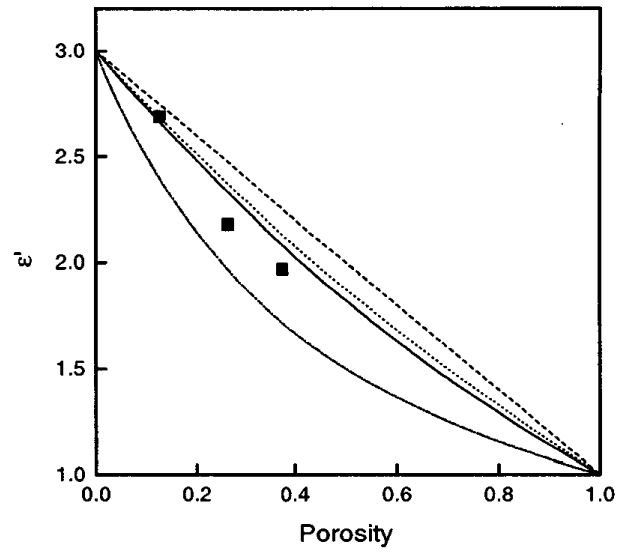

Figure 5. Dielectric constant ( $\varepsilon^{\prime}$ or $k$ ) versus porosity for Matrimid $^{\circledR}$ in comparison with four rules of mixtures: parallel model (dashed line, higher limit), Maxwell-Garnett theory (dotted line), Looyenga-Landau-Lifshitz theory (full line) and series model (dashed, lower limit).

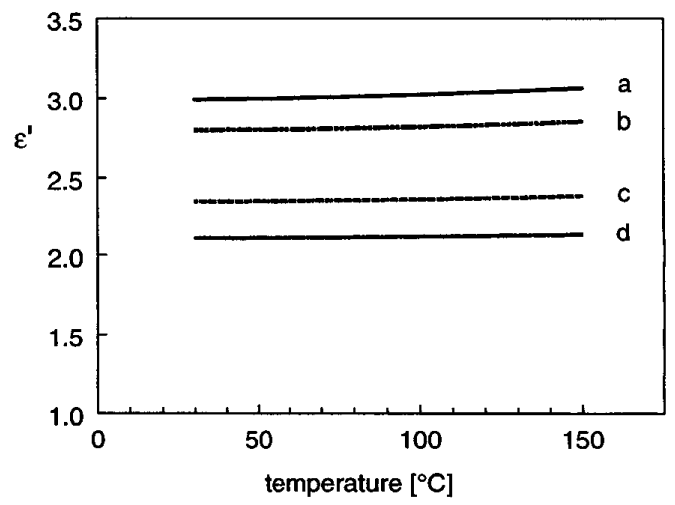

Figure 6. Dielectric constant of Matrimid $^{\circledR}$ versus temperature at $1 \mathrm{KHz}$. Porosities: a) unfoamed, b) $\mathrm{v}_{\text {air }}=0.126$, c) $\mathrm{v}_{\text {air }}=0.285$ and d) $\mathrm{v}_{\text {air }}=0.375$.

\section{CONCLUSIONS}

The results presented show a novel route for the preparation of thin ultra-low-k polymer films based on commercial and "non-exotic" (non-expensive) polyimide by a foaming technique. Dependent on the glass transition temperature of the polyimide mechanically and thermally stable $\left(>300{ }^{\circ} \mathrm{C}\right.$ ) films having porosities of ca. $40 \%$ and $\mathrm{k}$-values below 2.0 are formed. A further reduction into the ultra low $\mathrm{k}$ region may be accomplished by tailoring the shape of the pores from spherical into disc-like voids. 


\section{ACKNOWLEDGEMENTS}

The authors gratefully acknowledge the contributions of M. Chalid and P. J. Droppert for assistance with the dielectric measurements.

\section{REFERENCES}

[1] R. D. Miller, "In search of low-k dielectrics" Science, Vol. 283, pp. 421-423, 1999.

[2] G. Maier, " Low dielectric constant polymers for microelectronics" Prog. Polym. Sci., Vol. 26, pp. 3-65, 2001

[3] D. M. Stoakley, A. K. St. Clair, C. I. Croall, " Low dielectric, fluorinated polyimide copolymers, J. Appl. Polym. Sci., Vol. 51, pp. 1479 1483, 1994.

[4] J. L. Hedrick, K. R. Carter, J. W. Labadie, R. D. Miller, W. Volksen, C. J. Hawker, D. Y. Yoon, T. P. Russell, J. E. McGrath, R. M. Briber, "Nanoporous polyimides", Advances in Polym. Sci., Vol. 141, pp. 1-34, 1999.

[5] D. W. Kim, S. S. Hwang, S. M. Hong, H. O. Yoo, S. P. Hong, "Optimization of foaming process using triblock polyimides with thermally labile blocks", Polymer, Vol. 42, pp. 83-92, 2001.

[6] O. Gain, G. Seytre, J. Garapon, J. Vallet, B. Sillion, "Synthesis and characterization of porous polyimide films for dielectric applications", ACS Meeting: High-Temperature Properties and Application of Polymeric Materials, Vol. 603, pp. 201-213, 1994.

[7] S. Mikoshiba, S. Hayase, " Preparation of low density poly(methylsilsesquioxane)s for LSI interlayer dielectrics with low dielectric constant. Fabrication of Angstrom size pores prepared by baking trifluoropropylsilyl copolymers", J. Mater. Chem., Vol. 9, pp. 591-598, 1999.

[8] T. Takeichi, M. Zuo, A. Ito, "Preparation and properties of porous polyimide films", High Perform. Polym. Vol. 11, pp. 1-14, 1999.

[9] Y. Xu, Y. Tsai, K. N. Tu, B. Zhao, Q.-Z. Liu, M. Brongo, G. T. T. Sheng, C. H. Tung, "Dielectric property and microstructure of a porous polymer material with ultralow dielectric constant", Appl. Phys. Lett. Vol. 75, No. 6, pp. 853-855, 1999.

[10] B. Krause, R. Mettinkhof, N. F. A. van der Vegt, M. Wessling, "Microcellular foaming of amorphous high- $\mathrm{Tg}$ polymers using carbon dioxide:, Macromolecules, Vol. 34, No. 4, pp. 874-884, 2001 